\title{
The expression of low density lipoprotein receptor-related protein in colorectal carcinoma
}

\author{
KATRIN OBERMEYER ${ }^{1}$, SABINE KRUEGER ${ }^{1}$, BRIGITTE PETERS ${ }^{2}$, BERND FALKENBERG ${ }^{3}$, \\ ALBERT ROESSNER $^{1}$ and CHRISTOPH RÖCKEN ${ }^{4}$ \\ ${ }^{1}$ Department of Pathology, and ${ }^{2}$ Insitute for Biometrics and Medical Informatics, Otto-von-Guericke-University, Magdeburg; \\ ${ }^{3}$ Altmarkklinikum GmbH, Gardelegen, and ${ }^{4}$ Department of Pathology, Charité-University Hospital, Berlin, Germany
}

Received July 5, 2006; Accepted September 8, 2006

\begin{abstract}
Low density lipoprotein receptor-related protein (LRP) is a multifunctional cell surface receptor binding many different ligands including proteinases and their inhibitors, some of which are known to be involved in tumor biology. We studied the expression of LRP and its putative role in colorectal carcinoma. Tissue samples were obtained from 50 patients with colorectal carcinoma and fixed in formalin and embedded in paraffin. Immunohistochemical staining was performed using antibodies directed against LRP, cathepsin B and urokinase-type plasminogen activator (u-PA). The expression of LRP was further studied by polymerase chain reaction. The TNM stage was determined according to UICC guide lines and was based upon histological analysis. LRP was primarily expressed in stroma cells [36 patients (72\%)] and less frequently in tumor cells [6 patients (12\%)]. In $22 \%$ of all cases LRP was prominent at the invasion front. Cathepsin B was found both in the tumor stroma [50 (100\%)] and in the tumor cells [46 (92\%)]. u-PA was present in the tumor stroma [44 (88\%)] and in the tumor cells [44 (88\%)]. In stromal cells the expression of LRP correlated significantly with the expression of $\mathrm{u}-\mathrm{PA}(\mathrm{p}=0.043)$. Furthermore, the expression of LRP and of u-PA in tumor cells correlated with the tumor stage according to UICC ( $\mathrm{p}=0.038$ and 0.018 , respectively). We provide evidence that LRP is expressed in colorectal cancer. As LRP forms complexes with u-PA and its inhibitor, we suspect that LRP can influence the known effects of $\mathrm{u}-\mathrm{PA}$ on tumor biology.
\end{abstract}

\section{Introduction}

Colorectal cancer is the most common malignant tumor of the gastrointestinal tract (1). Its prognosis depends on many

Correspondence to: Professor Christoph Röcken, Department of Pathology, Charité-University Hospital, Schumannstr. 20/21, D-10117 Berlin, Germany

E-mail: christoph.roecken@charite.de

Key words: low densitiy lipoprotein receptor-related protein, cathepsin B, urokinase-type plasminogen activator, colorectal carcinoma, immunohistochemistry, PCR different factors, including local tumor growth, vascular invasion, reactive changes in regional lymph nodes, local signs of inflammation, completeness of tumor resection and distance of the tumor to the resection margins. The prognosis also depends on the histological grade of tumor differentiation, certain genetic markers and the expression of proteolytic enzymes (1).

There is abundant evidence that proteinases are involved in the tumor biology of colorectal cancer. Their ability to degrade components of the extracellular matrix (ECM) contributes to tumor cell invasion and metastasis (2). Former studies have shown that cathepsin $\mathrm{B}$ and $\mathrm{u}-\mathrm{PA}$ are among the proteinases expressed in colorectal cancer $(3,4)$.

Cathepsin B is a lysosomal cystein proteinase (5) that contributes directly to invasive growth and metastatic potential of malignant tumors by degrading ECM proteins $(2,6,7)$. Furthermore, cathepsin B can activate pro-u-PA, prorenin and procollagenase (8-10). In malignant cells cathepsin $\mathrm{B}$ could not only be found in lysosomes but also along the cell surface where its presence increases with the metastatic potential of the tumor cell $(11,12)$. Along the cellular membrane cathepsin B seems to be bound to $\alpha_{2}$-macroglobulin, which is in contact with the membrane via the low density lipoprotein receptor-related protein (LRP) (13).

The plasminogen activators $\mathrm{u}-\mathrm{PA}$ and t-PA are serine proteases. They convert plasminogen into active plasmin, which does not only act in thrombolysis but can also degrade components of the ECM $(2,14)$. Plasmin activates several prometalloproteinases that are also involved in the degradation of the ECM $(2,15,16)$. Even though those two plasminogen activators resemble each other in their structure and function, there are few differences. t-PA mainly seems to produce the active form of plasmin for thrombolysis whereas u-PA seems to be involved in processes of tissue rearrangement $(2,16,17)$. Pro-u-PA, the inactive single-chain form, is produced by many different malignant and non-neoplastic cells, including colorectal cancer $(18,19)$. Plasmin and cathepsin B can serve as activators of pro-u-PA $(9,16,19-21)$. On the cell surface pro-u-PA binds u-PAR and is then activated without losing its affinity to u-PAR. By binding to u-PAR proteolytic activity is concentrated on the cell surface and plasminogen activation increases by $\sim 16$-fold $(2,22,23)$. When u-PA is bound to u-PAR and reacts with its specific inhibitor PAI-1, the whole complex is endocytosed by an LRP-depending mechanism. LRP is 
Table I. Patient characteristics.

\begin{tabular}{|c|c|c|c|c|c|c|c|}
\hline \multirow[b]{2}{*}{$\begin{array}{l}\text { Characteristics } \\
\mathrm{n}(\%)\end{array}$} & & \multicolumn{2}{|c|}{ LRP } & \multicolumn{2}{|c|}{ Cathepsin B } & \multicolumn{2}{|c|}{$\mathrm{u}-\mathrm{PA}$} \\
\hline & & $\begin{array}{l}\text { Tumor } \\
\text { cells }\end{array}$ & $\begin{array}{l}\text { Desmoplastic } \\
\text { stroma }\end{array}$ & $\begin{array}{l}\text { Tumor } \\
\text { cells }\end{array}$ & $\begin{array}{c}\text { Desmoplastic } \\
\text { stroma }\end{array}$ & $\begin{array}{l}\text { Tumor } \\
\text { cells }\end{array}$ & $\begin{array}{c}\text { Desmoplastic } \\
\text { stroma }\end{array}$ \\
\hline Total $n=50$ & & $6 \quad(12)$ & $36 \quad(72)$ & $46 \quad(92)$ & $50(100)$ & $44 \quad(88)$ & $44 \quad(88)$ \\
\hline \multicolumn{8}{|l|}{ Sex } \\
\hline Male & $31(62)$ & $3 \quad(9.7)$ & $22(71.0)$ & $27(87.1)$ & 31 (100) & $26(83.9)$ & $26(83.9)$ \\
\hline Female & $19(38)$ & $3(15.8)$ & $14(73.7)$ & $19(100)$ & $19(100)$ & $18(94.7)$ & $18(94.7)$ \\
\hline \multicolumn{8}{|l|}{ Tumor localisation } \\
\hline Sigma & $20(40)$ & $3 \quad(15)$ & $16 \quad(80)$ & $19 \quad(95)$ & $20(100)$ & $19 \quad(95)$ & $19 \quad(95)$ \\
\hline Rectum & $22(44)$ & $2 \quad(9.1)$ & $14(63.6)$ & $21(95.5)$ & $22 \quad(44)$ & $19(86.4)$ & $19(86.4)$ \\
\hline Sigma and rectum & $8(16)$ & $1(12.5)$ & $6 \quad(75)$ & $8 \quad(100)$ & $8(100)$ & $6 \quad(75)$ & $6 \quad(75)$ \\
\hline \multicolumn{8}{|l|}{ TNM stages } \\
\hline $\mathrm{T} 1$ & $2 \quad(4)$ & 0 & 0 & $1 \quad(50)$ & $2(100)$ & $1 \quad(50)$ & $1 \quad(50)$ \\
\hline $\mathrm{T} 2$ & $10(20)$ & $3 \quad(30)$ & $6 \quad(60)$ & $10(100)$ & $10(100)$ & $6 \quad(60)$ & $7 \quad(70)$ \\
\hline $\mathrm{T} 3$ & $36(72)$ & $3 \quad(8.3)$ & $29(80.6)$ & 33 (91.7) & $36(100)$ & $35(97.2)$ & $33(91.7)$ \\
\hline $\mathrm{T} 4$ & 2 (4) & 0 & $1 \quad(50)$ & $2(100)$ & $2(100)$ & $2(100)$ & $2(100)$ \\
\hline N0 & $29(58)$ & $6(20.7)$ & $21(72.4)$ & $26(89.7)$ & $29(100)$ & $27(93.1)$ & $25(86.2)$ \\
\hline $\mathrm{N} 1$ & $12(24)$ & 0 & $8(66.7)$ & 12 (100) & $12(100)$ & $11(91.7)$ & $11(91.7)$ \\
\hline $\mathrm{N} 2$ & 7 (14) & 0 & 7 (100) & $6(85.7)$ & 7 (100) & $6(85.7)$ & 7 (100) \\
\hline $\mathrm{Nx}$ & $2 \quad(4)$ & 0 & 0 & $2(100)$ & $2(100)$ & $1 \quad(50)$ & $1 \quad(50)$ \\
\hline \multicolumn{8}{|l|}{ UICC stages } \\
\hline I & $9(18)$ & $3(33.3)$ & 4 (44.4) & $8(88.9)$ & $9(100)$ & $6(66.7)$ & $6(66.7)$ \\
\hline II & 22 (44) & $3(13.6)$ & $17(77.3)$ & $20(90.9)$ & $22 \quad(44)$ & $22(100)$ & $20(90.9)$ \\
\hline III & $19(38)$ & 0 & $15(78.9)$ & $18(94.7)$ & 19 (100) & $16(84.2)$ & $18(94.7)$ \\
\hline IV & 0 & 0 & 0 & 0 & 0 & 0 & 0 \\
\hline \multicolumn{8}{|l|}{ Grading } \\
\hline G1 & 0 & 0 & 0 & 0 & 0 & 0 & 0 \\
\hline $\mathrm{G} 2$ & 47 (94) & $6(12.8)$ & $35(74.5)$ & 43 (91.5) & 47 (100) & $42(89.4)$ & $42(89.4)$ \\
\hline G3 & $4 \quad(6)$ & 0 & $2(50.0)$ & $4 \quad(100)$ & $4(100)$ & $3(75.0)$ & $3(75.0)$ \\
\hline
\end{tabular}

binding u-PAR as well as the complex of u-PA:PAI-1 (24-26). This association of LRP and u-PAR is persistent in the early endosomes after internalisation of this whole complex. Then u-PA:PAI-1 separates from the receptor complex for degradation in lysosomes $(24,25)$. Vacant u-PAR and LRP now dissociate from each other and return to the cell surface via recycling vesicles, where they are available for new ligandbinding again $(24,25,27)$. This process is regulated by PAI on the one hand because it hinders u-PA from activating plasminogen and leads to the internalisation and degradation of u-PA. On the other hand it is regulated by LRP which is essential for this cellular uptake and the recycling of vacant receptors to the cell surface (24). In human trophoblast cells, blocking LRP by specific antibodies or by RAP leads to a $50 \%$ reduction of cell surface PA-activity and to a delayed regeneration of free u-PAR because, without LRP, inactivated complexes of u-PA:PAI-1 cannot be removed from the cell surface and vacant receptors cannot be recycled (28). Apart from its activation of plasminogen, u-PA is also involved in processes of cellular migration, adhesion, and differentiation via its link to PAI-1 and to u-PAR. PAI-1 has a high-grade affinity to vitronectin that can accelerate migration of smooth muscle cells significantly and to its receptor, vitronectin receptor integrin $\alpha_{v} \beta_{3}$, that is needed for cell motility. By binding to u-PA PAI-1 loses its affinity to vitronectin (29). u-PAR is associated with several cell surface integrins that are involved in cell-cell interactions, migration and adhesion (30,31). Furthermore, some signal pathways are initialized by binding $\mathrm{u}-\mathrm{PA}$ to $\mathrm{u}-\mathrm{PAR}$ that are again linked to cell migration and invasion (32-34).

Thus, while cathepsin B and u-PA have been found in colorectal cancer, and cellular metabolism of cathepsin B and $\mathrm{u}-\mathrm{PA}$ are regulated by LRP, to the best of our knowledge, until now the expression of LRP in colorectal cancer has not 
been studied. Here we investigated the expression of LRP in colorectal cancer, its spatial relation to cathepsin B and u-PA and whether it bears the potential of influencing colorectal cancer biology.

\section{Materials and methods}

Materials. Tissue samples from 50 patients (31 men, 19 women; mean age, 63.3 \pm 13.4 years; range, 35-91 years) suffering from cancer of the rectum or sigma were retrieved from the archive of the Department of Pathology of the Ottovon-Guericke-University, Magdeburg, Germany. All patients had undergone recto-sigmoidectomy between 1996 and 1998. Twenty-two of them were suffering from rectal cancer, 20 from sigmoidal cancer and 8 from cancer involving both, the sigma and rectum (Table I).

Tissue samples were collected directly after tumor resection and either snap-frozen in liquid nitrogen and stored at $-80^{\circ} \mathrm{C}$, or fixed in $4 \%$ buffered formalin and embedded in paraffin. For immunohistochemical staining tissue samples were chosen that enclosed tumor and non-neoplastic mucosa.

Histology. All resection specimens underwent routine surgical pathological examination, which included histological investigation of the tumor and non-neoplastic mucosa, the surgical margins and all lymph nodes present in the resection specimen. Deparaffinized sections were stained with hematoxylin and eosin. The TNM staging was determined according to the UICC guidelines (35).

Immunohistochemistry. For immunohistochemistry, 3- to 5- $\mu \mathrm{m}$ thick paraffin sections were placed onto SuperFrost $2+$ glass slides, deparaffinized in xylol (3x5 min) and rehydrated in a graded alcohol series (100, 100, 96 and $75 \%)$. Immunostaining was performed with murine monoclonal antibodies directed against LRP $\alpha$-chain (dilution 1:10), LRP $\beta$-chain (1:10; both American Diagnostica Inc., Greenwich, USA), u-PA (1:20; Technoclone, Vienna, Austria) and a sheep monoclonal antibody directed against cathepsin B (1:60; BioGenex Laboratories, San Ramon, USA). Incubation with the primary antibodies was carried out in a moist chamber at $37^{\circ} \mathrm{C}$ for $30 \mathrm{~min}$ (u-PA; cathepsin B) or $1 \mathrm{~h}$ (LRP). Biotinylated polyvalent anti-rabbit IgG (30 min, room temperature; Immunotech, Marseilles, France) or biotinylated mouse-anti-sheep antibodies (Dako, Hamburg, Germany) served as secondary antibodies. Slides were washed between steps with Tris-buffered saline (TBS). Immunoreactions were visualized via an avidinbiotin complex, using the Vectastain ABC alkaline phosphatase kit (Vector Laboratories Inc., Burlingame, USA) or the Ventana Nexes immunostainer and the Ventana Basic DAB detection kit (Ventana Medical Systems, Starsbourg, France). Fast red/ Naphthol Mx (Immunotech) or 3'3 diaminobenzidine served as chromogens. Immunostaining of LRP necessitated antigen retrieval with Proteinase $\mathrm{K}$ at $37^{\circ} \mathrm{C}$ for $30 \mathrm{~min}$. The specimens were counterstained with hematoxylin. Breast cancer tissue served as positive control. Omission of primary antibodies served as a negative control.

Polymerase chain reaction. LRP-mRNA was searched in unfixed tissue samples obtained from 12 of the patients also studied by immunohistochemistry. Using TRIzol reagent (Invitrogen), we extracted total cellular RNA according to the manufacturer's instructions. RNA was reverse-transcribed using oligo $(\mathrm{dT})_{12-18}$ primers by Omniscript ${ }^{\mathrm{TM}}$-reverse transcriptase (Qiagen $\mathrm{GmbH})$. Amplification of LRP cDNA was performed with the primers: LRP-1 3':5'-CTACTGGCTC GTTCTTGGCC-3' and 3v LRP-1 5':5'-CCTCATCTGAGC CGTCCATG-3'. The integrity of RNA and adequate cDNA synthesis was confirmed by using $B$-actin specific primers. Complete PCRs were initially heated to $94^{\circ} \mathrm{C}$ for $5 \mathrm{~min}$ for denaturation, and specific fragments were amplified in 30 cycles $\left(0.5 \mathrm{~min}\right.$ at $94^{\circ} \mathrm{C}, 1 \mathrm{~min}$ at 58 or $64^{\circ} \mathrm{C}$ and $1.5 \mathrm{~min}$ at $72^{\circ} \mathrm{C}$ ). The PCR products were analyzed on a $0.8 \%$ agarose gel stained with ethidium bromide. The oligonucleotide primers were custom synthesized by Invitek (Berlin, Germany).

Statistics. The correlation coefficient after Pearson and the $\chi^{2}$-test were used. A p-value of $<0.05$ was considered significant.

\section{Results}

LRP. Using a monoclonal antibody directed against the $\alpha$-chain of LRP we found LRP in the colorectal cancers of 47 (94\%) patients (Fig. 1). Immunostaining was usually faint and present in the non-neoplastic stroma cells [46 of 50 (92\%)], smooth muscle cells of the tunica muscularis [35 of $50(70 \%)]$ and tumor stroma cells [36 of $50(72 \%)$ ]. Adipose tissue was immunoreactive in 29 of 50 patients $(58 \%)$ and non-neoplastic epithelial cells in 8 of 50 patients $(16 \%)$. Colorectal cancer cells expressed LRP only in 6 of 50 patients (12\%). Interestingly, LRP-expression was inhomogenous, i.e., in $11(22 \%)$ patients immunostaining was more prominent at the invasion front and weaker or absent in the tumor centre. A similar expression pattern was found with an anti-LRP antibody directed against the B-chain. No immunostaining was observed after the omission of the primary antibody. Using PCR, we found LRP-mRNA in the tumor samples of 2 patients. In 10 patients LRP-mRNA was below detection level. In contrast, $B$-actin-mRNA was found in every case (Fig. 2).

Cathepsin B. Cathepsin B was found in every patient with colorectal cancer. It was present as strong cytoplasmic staining in neoplastic and non-neoplastic stromal and epithelial cells, in smooth muscle cells as well as in fat cells. Stroma cells showed very strong immunoreactivity (Fig. 1) in every case [50 of $50(100 \%)$ ]. Smooth muscle cells [47 of $50(94 \%)$ ], tumor cells [46 of $50(92 \%)$ ] (Fig. 1), and fat cells [43 of 50 $(86 \%)$ ] were immunoreactive for cathepsin B in most cases while non-neoplastic epithelial cells expressed cathepsin B in $28(56 \%)$ patients.

$u$-PA. u-PA was also found in all 50 patients. It was expressed by stromal and epithelial cells of the tumor and non-tumorous tissue, in smooth muscle cells and in fat cells, while each kind of cell was positive for u-PA in more than half of all cases. Immunoreactivity was especially strong in smooth muscle cells [47 of $50(94 \%)$ ], in non-neoplastic stromal cells [46 of $50(92 \%)$ ] (Fig. 1) in epithelial cells [41 of $50(82 \%)$, in 

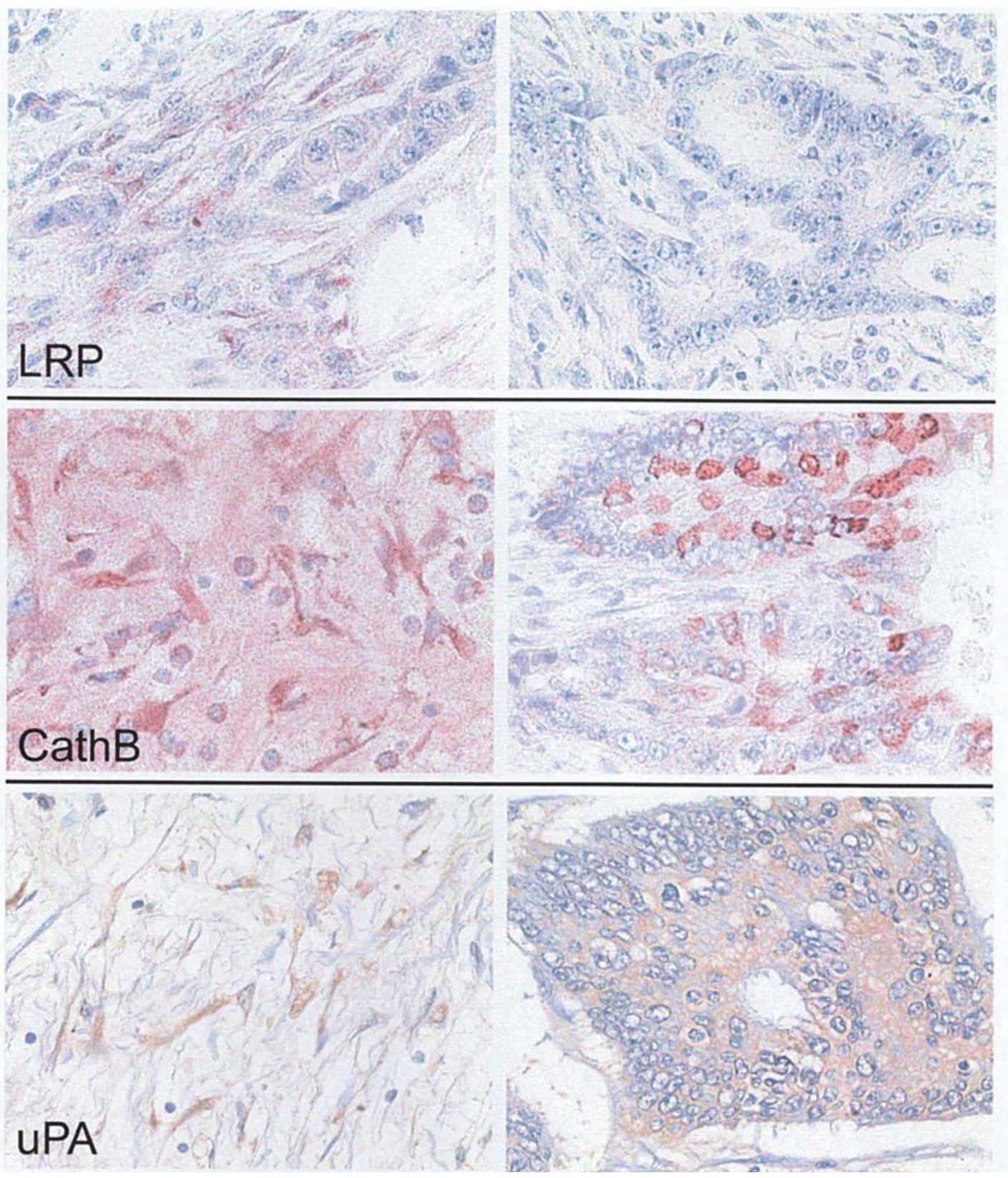

Figure 1. Immunohistochemical expression in colorectal cancers. The distribution and expression pattern of LRP, cathepsin B and u-PA in colorectal carcinomas was investigated by immunohistochemistry. Tumor tissues were stained with anti-LRP, anti-cathepsin B and anti-uPA antibodies. Cells of the desmoplastic stroma expressed LRP, cathepsin B and u-PA (left panel). Tumor cells often lacked immunoreactivity for LRP and were more commonly immunoreactive for cathepsin B and u-PA (right panel). Hematoxylin counterstain; original magnification, $\mathrm{x} 400$.



Figure 2. LRP-mRNA detected by polymerase chain reaction and subsequent agarose gel electrophoresis. LRP-mRNA (LRP-1) was found in the tumor tissue (TU) of two patients. NT denotes non-tumorous tissue. B-actin-mRNA served as positive control (bottom panel). tumor cells [44 of $50(88 \%)]$ and in cells of the tumor stroma [44 of $50(88 \%)]$.

Statistics. Statistical analyses showed a significant correlation between the prevalence of LRP- and u-PA-expression for smooth muscle cells $(\mathrm{p}=0.027)$ and cells of the tumor stroma $(\mathrm{p}=0.043)$. Furthermore, all samples were staged according to UICC classification. Concerning LRP, a significant correlation was found between the LRP-expression of tumor cells and tumor stage $(\mathrm{p}=0.038)$. $\mathrm{u}-\mathrm{PA}$ showed a significant correlation between the cells of non-neoplastic stroma $(\mathrm{p}=0.007)$ and tumor cells $(\mathrm{p}=0.018)$. The prevalence and spatial distribution of cathepsin B did not show any correlation with the expression of LRP, u-PA or any TNM-category. 




Figure 3. Interaction of LRP and u-PA according to Czekay et al (24). 1, active u-PA is bound to u-PAR and catalyses production of plasmin, by binding PAI-1 uPA is inactivated; 2, the complex of u-PA and PAI-1 binds to LRP and mediates the interaction of LRP and u-PAR; 3 , this complex of 4 components is being internalised; 4, u-PA:PAI dissociates from the receptors and is degraded; 5, LRP and u-PAR dissociate from each other; and 6, return to the cell surface in recycling vesicles.

\section{Discussion}

LRP is a member of the low density lipoprotein receptor family (LDLR family). This family comprises LRP, low density lipoprotein receptor (LDLR), very low density lipoprotein receptor (VLDLR), apolipoprotein E receptor 2 (ApoER2), multiple epidermal growth factor-containing protein 7, megalin/glycoprotein-330 (gp-330), MEGF7, LRP-1B, LRP-5 and LRP-6 (27,36-38). All of these proteins have some homologue domains in common but differ in their molecular masses and ligands (36). LRP consists of five domains: the ligand-binding cystein-rich repeats, the epidermal growth factor (EGF) receptor-like cystein-rich repeats, the YWTD domains, a membrane-spanning segment, and a cytoplasmatic tail that includes two NPxY motifs (2).

LRP is a cell surface receptor that can frequently be found in the liver, placenta and brain. It is also expressed by epithelial cells of the digestive system, smooth muscle cells, macrophages and fibroblasts $(39,40)$. It is characterized by its enormous number of different ligands and its wide spectrum of biological functions. The extracellular region with its four ligand-binding clusters recognizes at least 30 different ligands among which lipoproteins, proteinases and their inhibitors, proteins of the extracellular matrix (ECM), infectious agents such as bacterial toxins and viruses, and many other proteins can be found (41). At first, LRP was thought to primarily serve as a lipoprotein receptor due to its resemblance to LDLR (42-45). Later, LRP was found to bind the proteinase inhibitor $\alpha_{2}$-macroglobulin and it was discovered that it is identical to the $\alpha_{2}$-macroglobulin receptor $(42,46,47)$. The far biggest group of ligands however, seems to be formed by proteinases and their inhibitors among which the plasminogen activators t-PA and u-PA play a special role. LRP binds these proteinases as a complex with their inhibitors, such as PAI-1, to mediate their cellular uptake and lysosomal degradation $(25,26)$. Furthermore, LRP also binds to the special u-PA receptor (u-PAR) which is needed for the cellular uptake of u-PA:PAI-1 complexes (24).

We believe that we are the first to demonstrate the expression of LRP in colorectal cancer tissue. Despite using a relatively high concentration of the primary antibodies, we believe that immunostaining was specific for LRP for the following reasons: i) the negative controls never showed any immunoreaction excluding false positive staining related to the detection system or the secondary antibodies; ii) a second primary antibody directed against the $\beta$-chain of LRP showed a similar staining pattern to the antibody directed against the $\alpha$-chain; iii) the expression pattern of LRP observed in our series largely corresponds to observations made by others. LRP is supposed to be found mostly in cells of the stroma such as fibroblasts $(39,48,49)$. Moreover, cells of the central nervous system, hepatocytes, placental cells, adipocytes, monocytes, macrophages and smooth muscle cells express LRP (38-40). Here we found LRP in stromal cells, smooth muscle cells, in the tumor-accompanying desmoplastic stroma, and even in fat cells. These observations are in accordance with those described in the literature $(38,39,48,49)$. iv) Finally, LRP-mRNA was found by PCR in at least a few patients studied immunohistochemically. However, in the majority of our patients LRP-mRNA content was below the detection limit and might contribute to a low expression level.

In this study we found a decreasing expression of LRP in tumor cells with increasing tumor stages. Several other authors also showed decreasing LRP depending on the tumor stage (49-51). De Vries et al described a decline of the expression of LRP in highly progressive stages of melanocytic tumors (49). Other groups used LRP-deficient cells. These cells showed higher concentrations of u-PA and u-PAR, and their 
migration on vitronectin-covered surfaces and their invasion in matrigel was accelerated $(14,52)$. As accelerated invasion and migration are advantageous for malignant tumors, according to these observations rather low levels of LRP in malignant tumors would be suspected.

Other authors showed an increased expression of LRP in malignant tumors (53). This contradiction might be explained by the many different metabolic processes LRP takes place in. Increased availability of LRP on the cell surface can lead to an increased regeneration of free u-PAR that in turn binds $\mathrm{u}-\mathrm{PA}$ to the cell surface and, thus, increases the local proteolytic activity. Inactive pro-u-PA binds to u-PAR and is converted into its active form $\mathrm{u}-\mathrm{PA}$ that is proteolytically active and takes part in tumor biology $(22,23)$. If then PAI- 1 binds to $\mathrm{u}-\mathrm{PA}$ and inhibits its activity, the whole complex of those three proteins is taken up into the cell via LRP. u-PA and its inhibitor are degraded in lysosomes while LRP and u-PAR dissociate from each other and return to the cell surface in order to receive new ligands. Fig. 3 illustrates the biological mechanism of LRP-mediated $\mathrm{u}-\mathrm{PAR}$ recycling. As LRP is responsible for the uptake of this complex it might be assumed that an increased production of LRP could lead to an increase in proteolytic activity because it clears the cell surface from these inactive complexes and regenerates free u-PAR $(24,26)$. Yamamoto et al showed a correlation of increased expression of LRP, expression of u-PA, and malignancy of astrocytomas (53). Furthermore, Zhang et al demonstrated a decline in the activity of u-PA and reduction in the regeneration of free u-PAR when LRP was inhibited by RAP or antibodies (28). Cellular uptake and degradation of proteinases is not the only way in which LRP can influence tumor growth and metastasis. LRP is also responsible for the uptake of apo-E-enriched lipoproteins. Fabrizi et al showed reduced expression of LRP in differentiated cells of neuroblastoma and explained it with the lower demand for cholesterol and lipids of differentiated cells due to their lower mitotic index compared to dedifferentiated cells (54). It could be assumed that cells with high mitotic indices express more LRP because they need more cholesterol and lipids for membrane production. Maybe these circumstances lead to the higher expression of LRP in the invasion zone described in $22 \%$ of our samples.

In addition to LRP we also studied the expression of u-PA and cathepsin B in colorectal carcinoma. We found cathepsin $\mathrm{B}$ in tumor and accompanying tissue of each sample. For colorectal cancer the expression of cathepsin $\mathrm{B}$ has been described to correlate with the grade of differentiation and the tumor stage (3) and was not confirmed in our series. However, the number of cases was probably too small and we were mainly interested to show that LRP-expressing colorectal cancers also express cathepsin B. Similarly, we were able to show that LRP-expressing colorectal cancers also express u-PA in almost every patient. Thus, LRP is found in colorectal cancers that also express cathepsin B and u-PA.

When comparing the immunoreactivity of these three proteins, we were unable to find a correlation between cathepsin B and LRP, although it has been shown that cathepsin B is internalised via LRP (13). There was no correlation between cathepsin B and u-PA either. Again, others have shown that both, cathepsin B and u-PA, are taken up by colorectal cancer cells in the same caveolae (55).
Interestingly, we found statistically significant correlations between the expression of LRP and u-PA in smooth muscle cells and in the cells of the tumor stroma. This finding can be explained by LRP serving as a receptor for $\mathrm{u}-\mathrm{PA}$ and leading to its internalisation and degradation (26). LRP might also influence proteolytic activity and tumor biology of colorectal cancer by binding u-PA. Thus, increased expression of LRP might lead to an increased cellular uptake of u-PA and could concentrate proteolytic activity on the cell surface by binding u-PA. The latter would be advantageous for tumor cells by facilitating invasive growth.

In summary, we show here that colorectal cancers express LRP mainly in cells of the desmoplastic stroma and at the invasion front. Its expression correlates with the expression of u-PA. We assume that LRP influences tumor biology by interfering with the balance of activation and inhibition of proteolytic processes. This topic merits further investigation.

\section{References}

1. Hamilton SR and Aalton LA (eds): World Health Organisation of Tumors. Pathology and Genetics of Tumors of the Digestive System. IARC Press, Lyon, pp103-146, 2000.

2. Mignatti $P$ and Rifkin DB: Biology and biochemistry of proteinases in tumor invasion. Physiol Rev 73: 161-195, 1993.

3. Talieri M, Papadopoulou S, Scorilas A, Xynopoulos D, Arnogianaki N, Plataniotis G, Yotis J and Agnanti N: Cathepsin B and cathepsin D expression in the progression of colorectal adenoma to carcinoma. Cancer Lett 205: 97-106, 2004.

4. Grondahl-Hansen J, Ralfkiaer E, Kirkeby LT, Kristensen P, Lund LR and Dano K: Localisation of urokinase-type plasminogen activator in stromal cells in adenocarcinomas of the colon in humans. Am J Pathol 138: 111-117, 1991.

5. Kirschke H, Barrett AJ and Rawlings ND: Proteinases 1: lysosomal cysteine proteinases. In: Protein Profile. Vol. 2. Sheterline P (ed). Academic Press, London, pp1587-1591, 1995.

6. Buck MR, Karustis DG, Day NA, Honn KV and Sloane BF: Degradation of extracellular-matrix proteins by human cathepsin B from normal and tumour tissues. Biochem J 282: 273-278, 1992.

7. Lah TT, Buck MR, Honn KV, Crissman JD, Nagesawa CR, Liotta LA and Sloane BF: Degradation of laminin by human tumor cathepsin B. Clin Exp Metastasis 7: 461-468, 1989.

8. Eeckhout Y and Vaes G: Further studies on the activation of procollagenase, the latent precursor of bone collagenase. Effects of lysosomal cathepsin B, plasmin and kallikrein, and spontaneous activation. Biochem J 166: 21-31, 1977.

9. Kobayashi H, Schmitt M, Goretzki L, Chucholowski N, Calvete J, Kramer M, Gunzler WA, Janicke F and Graeff H: Cathepsin B efficiently activates the soluble and the tumor cell receptorbound form of the proenzyme urokinase-type plasminogen activator (Pro-uPA). J Biol Chem 266: 5147-5152, 1991.

10. Wang PH, Do YS, Macaulay L, Shinagawa T, Anderson PW, Baxter JD and Hsueh WA: Identification of renal cathepsin B as a human prorenin-processing enzyme. J Biol Chem 266: 12633-12638, 1991 .

11. Sameni M, Elliott E, Ziegler G, Fortgens PH, Dennison C and Sloane BF: Cathepsin B and D are localized at the surface of human breast cancer cells. Pathol Oncol Res 1: 43-53, 1995.

12. Sloane BF, Rozhin J, Johnson K, Taylor H, Crissman JD and Honn KV: Cathepsin B: association with plasma membrane in metastatic tumors. Proc Natl Acad Sci USA 83: 2483-2487, 1986.

13. Arkona $\mathrm{C}$ and Wiederanders B: Expression, subcellular distribution and plasma membrane binding of cathepsin $\mathrm{B}$ and gelatinases in bone metastatic tissue. Biol Chem 377: 695-702, 1996.

14. Werb Z, Banda MJ and Jones PA: Degradation of connective tissue matrices by macrophages. I. Proteolysis of elastin, glycoproteins and collagen by proteinases isolated from macrophages. J Exp Med 152: 1340-1357, 1980.

15. Murphy G, Ward R, Gavrilovic J and Atkinson S: Physiological mechanisms for metalloproteinase activation. Matrix Suppl 1: S224-S230, 1992. 
16. Skrzydlewska E, Sulkowska M, Koda M and Sulkowski S: Proteolytic-antiproteolytic balance and its regulation in carcinogenesis. World J Gastroenterol 11: 1251-1266, 2005.

17. Dano K, Andreasen PA, Grondahl-Hansen J, Kristensen P, Nielsen LS and Skriver L: Plasminogen activators, tissue degradation and cancer. Adv Cancer Res 44: 139-266, 1985.

18. Eaton DL, Scott RW and Baker JB: Purification of human fibroblast urokinase proenzyme and analysis of its regulation by proteases and protease nexin. J Biol Chem 259: 6241-6247, 1984.

19. Petersen LC, Lund LR, Nielsen LS, Dano K and Skriver L: One-chain urokinase-type plasminogen activator from human sarcoma cells is a proenzyme with little or no intrinsic activity. J Biol Chem 263: 11189-11195, 1988.

20. Blasi F, Vassalli JD and Dano K: Urokinase-type plasminogen activator: proenzyme, receptor and inhibitors. J Cell Biol 104: 801-804, 1987.

21. Kasai S, Arimura H, Nishida M and Suyama T: Proteolytic cleavage of single-chain pro-urokinase induces conformational change which follows activation of the zymogen and reduction of its high affinity for fibrin. J Biol Chem 260: 12377-12381, 1985.

22. Cubellis MV, Nolli ML, Cassani G and Blasi F: Binding of single-chain prourokinase to the urokinase receptor of human U937 cells. J Biol Chem 261: 15819-15822, 1986.

23. Ellis V, Scully MF and Kakkar VV: Plasminogen activation by single-chain urokinase in functional isolation. A kinetic study. J Biol Chem 262: 14998-15003, 1987.

24. Czekay RP, Kuemmel TA, Orlando RA and Farquhar MG: Direct binding of occupied urokinase receptor (UPAR) to LDL receptor-related protein is required for endocytosis of UPAR and regulation of cell surface urokinase activity. Mol Biol Cell 12: 1467-1479, 2001

25. Herz J, Clouthier DE and Hammer RE: LDL receptor-related protein internalizes and degrades uPA-PAI- 1 complexes and is essential for embryo implantation. Cell 71: 411-421, 1992.

26. Nykjaer A, Petersen CM, Moller B, Jensen PH, Moestrup SK, Holtet TJ, Etzerodt M, Thgersen HC, Munch M, Andreasen PA and Gliemann J: Purified $\alpha 2$-macroglobulin receptor/LDL receptor-related protein binds urokinase plasminogen activator inhibitor type-1 complex. J Biol Chem 267: 14543-14546, 1992.

27. Strickland DK, Kounnas MZ and Argraves WS: LDL receptorrelated protein: a multiligand receptor for lipoprotein and proteinase catabolism. FASEB J 9: 890-898, 1995 .

28. Zhang JC, Sakthivel R, Kniss D, Graham CH, Strickland DK and McCrae KR: The low density lipoprotein receptor-related protein/ $\alpha 2$-macroglobulin receptor regulates cell surface plasminogen activator activity on human trophoblast cells. J Biol Chem 273: 32273-32280, 1998.

29. Stefansson S and Lawrence DA: The serpin PAI-1 inhibits cell migration by blocking integrin alpha $\mathrm{v}$ beta 3 binding to vitronectin. Nature 383: 441-443, 1996.

30. Bohuslav J, Horejsi V, Hansmann C, Stockl J, Weidle UH, Majdic O, Bartke I, Knapp W and Stockinger H: Urokinase plasminogen activator receptor, beta 2-integrins and Src-kinases within a single receptor complex of human monocytes. J Exp Med 181: 1381-1390, 1995.

31. Tarui T, Mazar AP, Cines DB and Takada Y: Urokinase-type plasminogen activator receptor (CD87) is a ligand for integrins and mediates cell-cell interaction. J Biol Chem 276: 3983-3990, 2001.

32. Nguyen DHD, Webb DJ, Catling AD, Song Q, Dhakephalkar A, Weber MJ, Ravichandran KS and Gonias SL: Urokinase-type plasminogen activator stimulates the Ras/Extracellular signalregulated kinase (ERK) signaling pathway and MCF-7 cell migration by a mechanism that requires focal adhesion kinase, Src and Shc. Rapid dissociation of GRB2/Sps-Shc complex is associated with the transient phosphorylation of ERK in urokinasetreated cells. J Biol Chem 275: 19382-19388, 2000.

33. Sitrin RG, Pan PM, Harper HA, Blackwood RA and Todd RF III: Urokinase receptor (CD87) aggregation triggers phosphoinositide hydrolysis and intracellular calcium mobilization in mononuclear phagocytes. J Immunol 163: 6193-6200, 1999.

34. Webb DJ, Nguyen DHD and Gonias S: Extracellular signalregulated functions in the urokinase receptor-dependent pathway by which neutralization of low density lipoprotein receptorrelated protein promotes fibrosarcoma cell migration and Matrigel invasion. J Cell Sci 113: 123-134, 2000.

35. Wittekind CH and Sobin LH: TNM Classification of Malignant Tumours. 6th edition. Wiley-Liss, Inc., 2002.

36. Boucher P and Gotthardt M: LRP and PDGF signaling: a pathway to atherosclerosis. Trends Cardiovasc Med 14: 55-60, 2004.
37. Herz $\mathrm{J}$ and Willnow TE: Functions of the LDL receptor gene family. Ann NY Acad Sci 737: 14-19, 1994.

38. Moestrup SK: The $\alpha 2$-macroglobulinreceptor and epithelial glycoprotein-330: two giant receptors mediating endocytosis of multiple ligands. Biochem Biophys Acta 1197: 197-213, 1994.

39. Moestrup SK, Kalthoft K, Petersen CM, Pedersen S, Gliemann J and Christensen EI: Immunocytochemical identification of the human $\alpha 2$-macroglobulin receptor in monocytes and fibroblasts: monoclonal antibodies define the receptor as a monocyte differentiation antigen. Exp Cell Res 190: 195-203, 1990.

40. Moestrup SK, Gliemann J and Pallesen G: Distribution of the $\alpha 2$-macroglobulin receptor/low density lipoprotein receptorrelated protein in human tissues. Cell Tissue Res 269: 375-382, 1992.

41. Herz J and Strickland DK: LRP: a multifunctional scavenger and signaling receptor. J Clin Invest 108: 779-784, 2001.

42. Brown MS, Herz J, Kowal RC and Goldstein JL: The lowdensity lipoprotein receptor-related protein: double agent or decoy? Curr Opin Lipid 2: 65-72, 1991.

43. Herz J, Hamann U, Rogne S, Myklebost O, Gausepohl H and Stanley KK: Surface location and high affinity for calcium of a 500 -kd liver membrane protein closely related to the LDLreceptor suggest a physiological role as lipoprotein receptor. EMBO J 7: 4119-4127, 1988.

44. Kowal RC, Herz J, Goldstein JL, Esser V and Brown MS: Low density lipoprotein receptor-related protein mediates uptake of cholesteryl esters derived from apoprotein E-enriched lipoproteins. Proc Natl Acad Sci USA 86: 5810-5814, 1989.

45. Rohlmann A, Gotthardt M, Hammer RE and Herz J: Inducible inactivation of hepatic LRP gene by cre-mediated recombination confirms role of LRP in clearance of chylomicron remnants. J Clin Invest 101: 689-695, 1998.

46. Moestrup SK and Gliemann J: Purification of the rat hepatic $\alpha 2-$ macroglobulin receptor as an approximately 440-kDa single chain protein. J Biol Chem 264: 15574-15577, 1989.

47. Strickland DK, Ashcom JD, Williams S, Burgess WH, Migliorni M and Argraves WS: Sequence identity between the a2-macroglobulin receptor and low density lipoprotein receptorrelated protein suggests that this molecule is a multifunctional receptor. J Biol Chem 265: 17401-17404, 1990.

48. Christensen L, Wiborg Simonsen AC, Heegard CW, Moestrup SK, Andersen JA and Andreasen PA: Immunohistochemical localisation of urokinase-type plasminogen activator, type-1 plasminogen-activator inhibitor, urokinase receptor and $\alpha 2-$ macroglobulin receptor in human breast carcinomas. Int $\mathbf{J}$ Cancer 66: 441-452, 1996.

49. De Vries TJ, Verheijen JH, De Bart AWC, Weidle UH, Ruiter DJ and van Muijen GNP: Decreased expression of both the lowdensity lipoprotein receptor-related protein/ $\alpha 2$-macroglobulin receptor and its receptor-associated protein in late stages of cutaneous melanocytic tumor progression. Cancer Res 56: 1432-1439, 1996.

50. Desrosiers RR, Rivard ME, Grundy PE and Annabi B: Decrease in LDL receptor-related protein expression and function correlates with advanced stages of Wilms tumors. Pediatr Blood Cancer 46: 40-49, 2006

51. Kancha RK, Stearns ME and Hussain MM: Decreased expression of the low density lipoprotein receptor-related protein/ $\alpha 2-$ macroglobulin receptor in invasive cell clones derives from human prostate and breast tumor cells. Oncol Res 6: 365-372, 1994.

52. Weaver AM, Hussaini IM, Mazar A, Henkin J and Gonias SL: Embryonic fibroblasts that are genetically deficient in low density lipoprotein receptor-related protein demonstrate increased activity of the urokinase receptor system and accelerated migration on vitronectin. J Biol Chem 272: 14372-14379, 1997.

53. Yamamoto M, Ikeda K, Ohshima K, Tsugu H, Kimura $\mathrm{H}$ and Tomonaga M: Increased expression of low density lipoprotein receptor-related protein/ $\alpha 2$-macroglobulin receptor in human malignant astrocytomas. Cancer Res 57: 2799-2805, 1997.

54. Fabrizi C, Businaro R, Persichini T, Fumagalli L and Lauro GM: The expression of the LDL receptor-related protein (LRP) correlates with the differentiation of human neuroblastoma cells. Brain Res 776: 154-161, 1997.

55. Cavallo-Medved D, Mai J, Dosescu J, Sameni M and Sloane BF: Caveolin-1 mediates the expression and localization of cathepsin B, pro-urokinase plasminogen activator and their cellsurface receptors in human colorectal carcinoma cells. J Cell Sci 118: 1493-1503, 2005. 